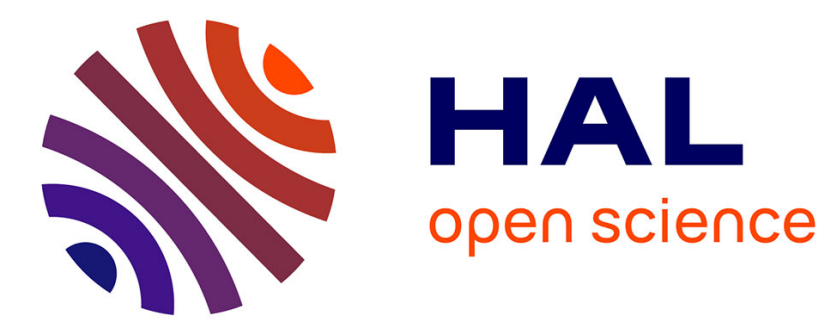

\title{
Estrogen regulation of epithelial ion transport: Implications in health and disease
}

Vinciane Saint-Criq, Raphaël Rapetti-Mauss, Yamil Yusef, Brian Harvey

\section{To cite this version:}

Vinciane Saint-Criq, Raphaël Rapetti-Mauss, Yamil Yusef, Brian Harvey. Estrogen regulation of epithelial ion transport: Implications in health and disease. Steroids, 2012, 77 (10), pp.918-923. 10.1016/j.steroids.2012.02.017 . hal-02348840

\section{HAL Id: hal-02348840 \\ https://hal.science/hal-02348840}

Submitted on 10 Dec 2019

HAL is a multi-disciplinary open access archive for the deposit and dissemination of scientific research documents, whether they are published or not. The documents may come from teaching and research institutions in France or abroad, or from public or private research centers.
L'archive ouverte pluridisciplinaire HAL, est destinée au dépôt et à la diffusion de documents scientifiques de niveau recherche, publiés ou non, émanant des établissements d'enseignement et de recherche français ou étrangers, des laboratoires publics ou privés. 
Review

\title{
Estrogen regulation of epithelial ion transport: Implications in health and disease
}

\author{
Vinciane Saint-Criq, Raphael Rapetti-Mauss, Yamil R. Yusef, Brian J. Harvey* \\ Department of Molecular Medicine, Royal College of Surgeons in Ireland (RCSI), Education E Research Centre, Beaumont Hospital, Dublin 9, Ireland
}

\section{A R T I C L E I N F O}

\section{Article history:}

Received 20 December 2011

Received in revised form 29 January 2012

Accepted 23 February 2012

Available online 5 March 2012

\section{Keywords:}

Estrogen

Ion channels

Epithelia membrane transport

\begin{abstract}
A B S T R A C T
Estrogen, $17 \beta$-estradiol (E2), has been shown to modulate the activity of ion channels in a diverse range of epithelial tissues. The channel activation or inhibition responses to E2 are often rapid, occurring in seconds to minutes, independent of protein synthesis and gene transcription ('non-genomic' response). These rapid effects of E2 require activation of specific protein kinases or changes in intracellular calcium and $\mathrm{pH}$ which in turn modulate the conductance, open probability or number of channels in the plasmamembrane. Estrogen has also been shown to affect the expression of ion transporters over days ('genotropic' response) causing long-term sustained changes in transepithelial ion transport. It is now accepted that so called non-genomic responses are not stand-alone events and are necessary to prime the latent genomic response and even be critical for the full latent response to occur. In a number of epithelia the non-genomic and genotropic responses to estrogen are sex-specific and variable in potency and sensitivity to E2 depending on the stage of the estrous cycle. Of increasing interest is the effect these rapid and latent actions of E2 on ion transporters have on the physiological functions of epithelia. For example, estrogen regulation of a class of voltage-gated $\mathrm{K}^{+}$channels (KCNQ1) can determine the rate of $\mathrm{Cl}^{-}$secretion in the intestine. In whole-body terms, the combined effects of estrogen on a variety of ion channels which control fluid and electrolyte transport in the kidney, intestine and lung may be necessary for endometrial expansion and implantation of the blastocyte.
\end{abstract}

(c) 2012 Elsevier Inc. All rights reserved.

\section{Contents}

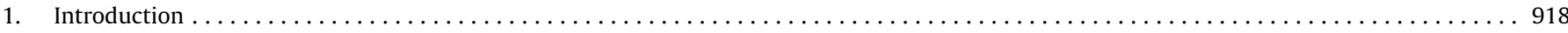

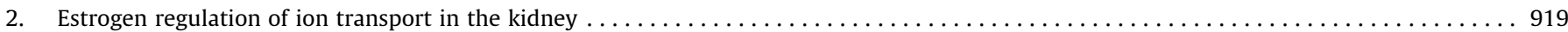

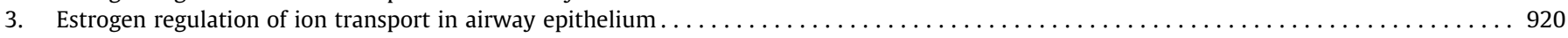

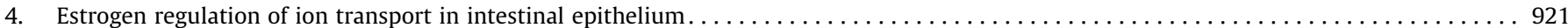

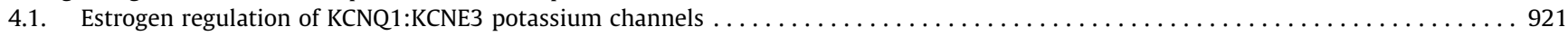

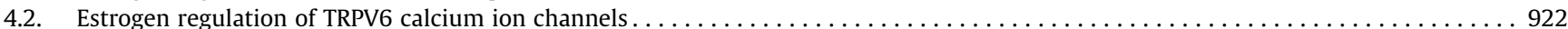

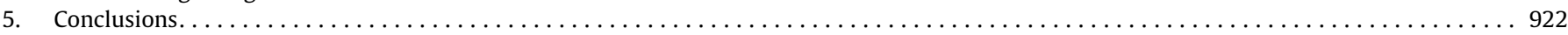

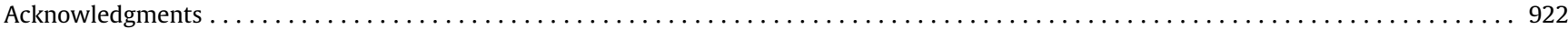

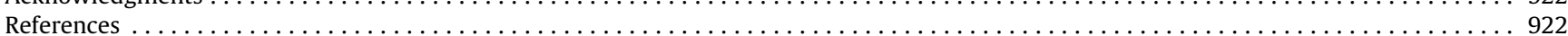

\section{Introduction}

The physiology and pathophysiology of estrogen effects on ion channels and transporters in epithelial tissues is of topical interest.

\footnotetext{
Abbreviations: E2, 17 $\beta$ estradiol; ENaC, Epithelial Sodium Channel; CCD, cortical collecting duct.

* Corresponding author. Address: Department of Molecular Medicine, Royal College of Surgeons in Ireland (RCSI), Education \& Research Centre, Beaumont Hospital, P.O. Box 9063, Dublin 9, Ireland. Tel.: +353 1 8093817; fax: +353 1 8093774.

E-mail address: bjpharvey@rcsi.ie (B.J. Harvey).
}

Epithelial ion channels play a critical role in the maintenance of whole body fluid balance and in the progression of common diseases such as secretory diarrhea and cancer cell proliferation. The extra-gonadal effects of estrogen on ion channels and transporters are female-sex specific and both rapid 'non-genomic' and genomic in their cell signaling patterns. In healthy tissues, estrogen modulation of ion channel activity and transporters appear to have beneficial effects. For example, estrogen produces a rapid onset and sustained anti-secretory response in intestinal epithelia by inhibiting chloride ion secretion via inactivation of KCNQ1:KCNE3 channels (Fig. 1). The positive effects on organ physiology may be 


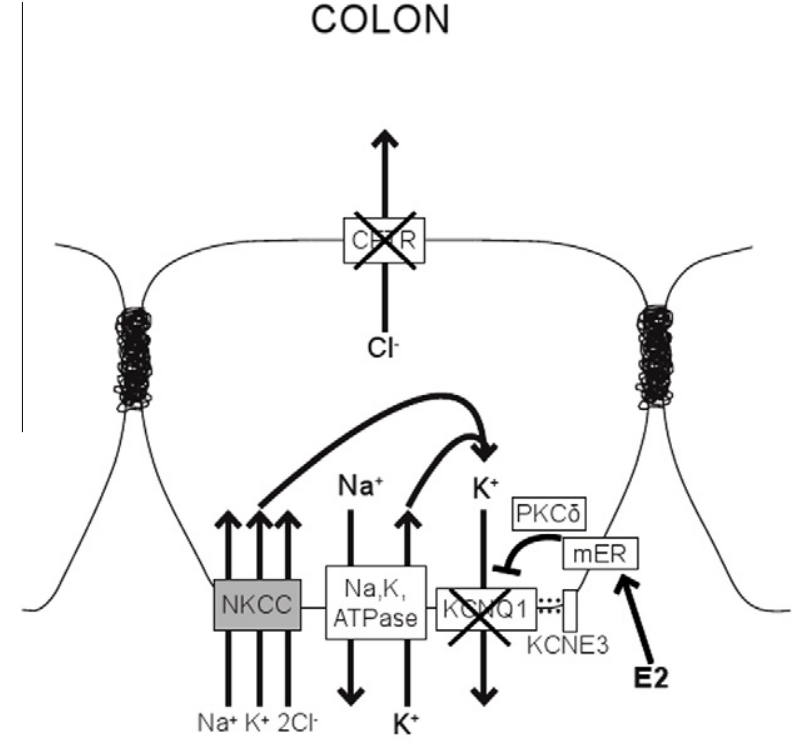

Anti-secretory action of E2 in colonic epithelium Estrogen prevents diarrhea.

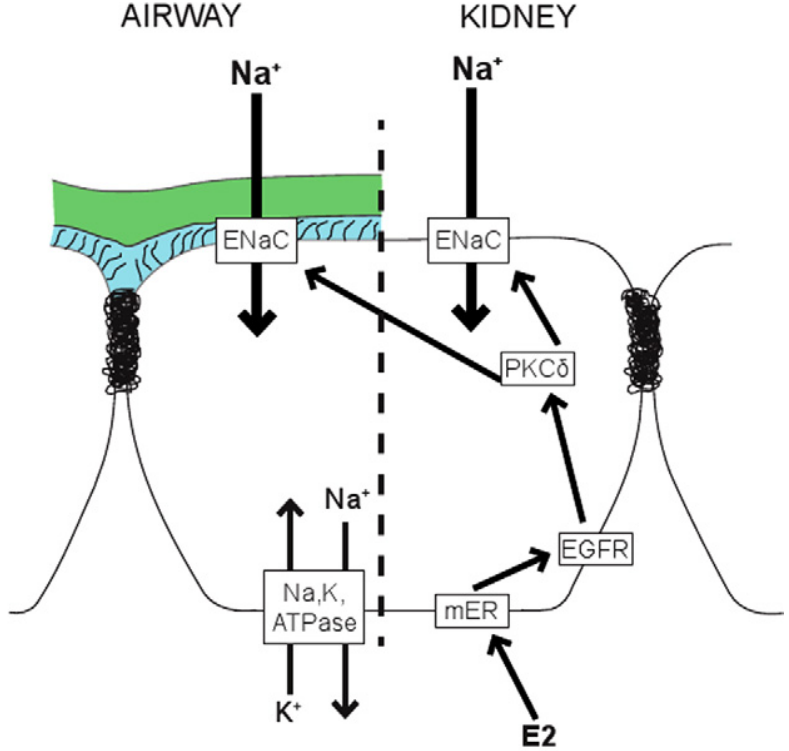

Pro-absorptive action of E2 in airway and renal epithelium Estrogen exacerbates cystic fibrosis and promotes water retention.

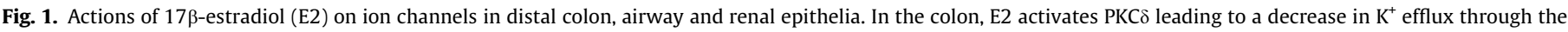

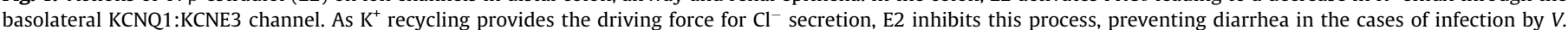

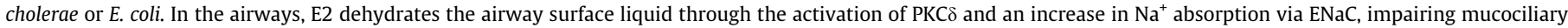

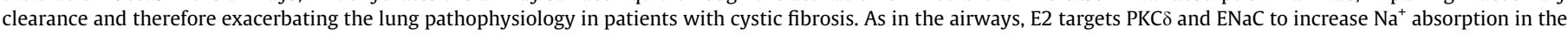
kidney, showing that E2 is an important player in the regulation of the electrolyte and fluid transport in this organ.

to prevent secretory diarrhea in high estrogen states when extracellular fluid (ECF) volume needs to be conserved (for example during blastocyst implantation into the swollen endometrium). Reproductive females experience the inconvenience of fluid retention during high estrogen states in mid-estrus cycle and 'bloating' or excessive fluid retention is a common feature of estrogen treatment in assisted fertilization. It has been postulated that the antisecretory effects of estrogen in the intestine contribute to ECF volume expansion during the implantation window [1]. Such an effect may be short-circuited by compensatory $\mathrm{Na}^{+}$and water excretory mechanisms in the kidney or insensible transpiration in the lung. However, estrogen exerts pro-absorptive effects in bronchial airway epithelium and in kidney cortical collecting duct cells by rapidly activating ENaC and transepithelial $\mathrm{Na}^{+}$absorption (Fig. 1). Thus the major ECF regulatory organs contribute to the overall physiological response to estrogen, causing ECF expansion to permit implantation (Fig. 1). The deleterious consequences of estrogen action on epithelial ion channels appears to be confined to diseased tissues where ion absorption/secretion is already compromised such as the airways in cystic fibrosis or in breast cancer where ion channel activation may amplify proliferative signals. Thus for example, the influence of estrogen on ion channel activity in epithelia may change the course of a disease, such as in the gender gap of cystic fibrosis where the pro-absorptive and anti-secretory effects of estrogen can reduce airway fluid dynamics thus exacerbating mucociliary clearance and lung function (Fig. 1). We are currently at the pioneering stage of understanding estrogen actions on ion channels and transporters in general and the consequences in health and disease. Much is yet to be uncovered in the underlying physiology and molecular mechanisms of rapid estrogen responses in epithelia, in particular, with respect to the sexual dimorphism of extra-gonadal effects of estrogen on ion channels. In this review we focus on estrogen and ion channels in kidney, lung and intestinal epithelia, in health and disease, giving an insight into the current state-of-the-art as well as promising areas for future research.

\section{Estrogen regulation of ion transport in the kidney}

One of the main physiological functions attributed to the kidney is the regulation of water and electrolyte content of the body. This function is performed by its basic structural and functional unit, the nephron. In the distal nephron, the cortical collecting duct (CCD) plays a critical role in the hormonal control of electrolyte and fluid homeostasis and it has been shown that these processes can be tightly regulated by the hormones insulin, vasopressin and aldosterone [2-12]. The rapid non-genomic actions of aldosterone on renal ion transporters has been well-described [13-18]. Aldosterone regulates $\mathrm{CCD} \mathrm{Na}{ }^{+}$reabsorption in a rapid non-genomic and genomic manner; this regulation involves changes in Epithelial Sodium Channel (ENaC) expression, trafficking dynamics, stability at the plasma membrane and changes in open channel probability [29-31].

For many years, it has been shown that $17 \beta$-estradiol (E2) has an impact in the control of whole body electrolyte and fluid homeostasis [19-22], however, it is only in the last decade that the targets and molecular mechanisms involved in this regulation have started to be identified [23-25]. The kidney has been proposed as an estrogen-responsive target where E2 could exert a pro-absorptive effect [23]. Moreover, a possible role of E2 in stimulation of renal $\mathrm{K}^{+}$secretion [24], $\mathrm{Ca}^{2+}$ signaling [15,25,26], $\mathrm{pH}$ homeostasis [27] and the rennin-angiotensin pathway [28] has been proposed.

Evidence suggesting a long-term sex-specific pro-absorptive effect for E2 in the kidney have been published in recent years $[32,33]$. In rat kidney, it has been shown that the abundance of $\alpha-, \beta$ - and $\gamma$-ENaC subunit mRNA was significantly higher in female compared to male rat kidneys. These sex differences were abolished in ovariectomized rats and treatment of ovariectomized rats with E2 increased renal $\alpha$-ENaC subunit mRNA levels over long periods up to $24 \mathrm{~h} \mathrm{[32].} \mathrm{Another} \mathrm{study,} \mathrm{in} \mathrm{a} \mathrm{diabetic} \mathrm{rat} \mathrm{model,}$ has shown that E2 causes diabetes dependent and independent 
effects on renal electrolyte handling and associated transporter proteins [33]. In mouse collecting tubular cells, E2 or progesterone alone increased ENaC activity and a low concentration of E2 together with progesterone produced an additive stimulation of ENaC activity [34]. Ovariectomized female rats treated with E2 also showed an increase in plasma $\mathrm{Na}^{+}$concentration [35]. Furthermore, this study has shown that in aldosterone-infused female rats, plasma $\mathrm{Na}^{+}$was increased further than in male rats infused with aldosterone [35], suggesting a regulatory role for E2 on the renin-angiotensin-aldosterone system (RAAS) [28].

The evidence described above involves only long-term effects for $\mathrm{E} 2$ on $\mathrm{Na}^{+}$reabsorption and, in contrast, little is known about the E2 short-term effects on renal transport processes. Recently, we have found evidence for a rapid E2 pro-absorptive effect in the distal nephron via stimulation of ENaC activity. The rapid E2 activation ( $<15 \mathrm{~min}$ ) of amiloride-sensitive $\mathrm{Na}^{+}$current in mouse M1 CCD cells was sensitive to inhibitors of PKC $\delta$ and ER $\alpha$ (Yusef \& Harvey, unpublished).

As for the case of $\mathrm{Na}^{+}$reabsorption, $\mathrm{K}^{+}$secretion in the kidney can be tightly regulated by aldosterone. The classical mechanism involves an increase in the expression of the $\mathrm{Na}^{+} / \mathrm{K}^{+}$-ATPase at the basolateral membrane of principal cells of the CCD and a subsequent increase in the driving force for $\mathrm{K}^{+}$secretion through the Renal Outer Medullary Potassium channel (ROMK) [36]. A second and more novel mechanism is related to situations of high plasma $\mathrm{K}^{+}$concentration where an increase of plasma aldosterone leads to repression of signaling pathways involved in the inhibition of apical $\mathrm{K}^{+}$channels such as ROMK and BK [25]. However, a possible regulation of $\mathrm{K}^{+}$secretion by E2 in the kidney has not been established. Inspired by the observation that polycystic kidney disease has worse prognosis in men, a study performed in MDCK cells has shown that testosterone stimulates fluid secretion by increasing cAMP levels but failed in showing any effect for E2 [37]. On the other hand, a more recent study has shown that in aldosterone-infused female rats, plasma $\mathrm{K}^{+}$concentration was reduced further than in male rats infused with aldosterone. Furthermore E2 but not progesterone reduced plasma $\mathrm{K}^{+}$concentration in ovariectomized female rats [35]. These observations provide another piece of evidence supporting a possible regulatory effect of E2 on RAAS.

In recent years data supporting a novel role for E2 to rapidly regulate $\mathrm{Ca}^{2+}$ homeostasis in the kidney has been shown $[25,26,38]$. E2 can rapidly modulate intracellular $\mathrm{Ca}^{2+}$ levels through a $\mathrm{Ca}^{2+}$ entry pathway in kidney M1 cells [15]. Moreover, it has been shown that TRPV5, a $\mathrm{Ca}^{2+}$-permeable cation channel member of the Transient Receptor Potential channel subfamily, is responsible for the rapid and transient increase in whole-cell currents and intracellular $\mathrm{Ca}^{2+}$ concentration $\left(\left[\mathrm{Ca}^{2+}\right]_{i}\right)$ induced by $\mathrm{E} 2$ in rat CCD cells [26]. A more recent study has shown acute actions of E2 on intracellular $\mathrm{Ca}^{2+}$ signaling in intercalated cells from isolated distal convoluted tubules, connecting tubules and initial cortical collecting ducts [27]. It has been postulated that the E2 induced $\left[\mathrm{Ca}^{2+}\right]_{i}$ increases and enhanced $\mathrm{H}^{+}$-ATPase activity may occur through the activation of the membrane associated estrogen receptor, GPER1 [27].

Although the current literature is scarce on E2 regulation of kidney ion transport recent evidence points to a previously unknown role of E2 as an important player in the regulation of the electrolyte and fluid transport in the kidney, its potential role in the regulation of RAAS and a non-genomic regulation of ENaC.

\section{Estrogen regulation of ion transport in airway epithelium}

The epithelium lining the lung is covered by a thin layer of fluid that provides a barrier against inhaled pathogens and particles. In the bronchi, the airway surface liquid (ASL) covers the bronchial epithelial cells and is composed of two layers. The periciliary layer has a low viscosity to allow beating cilia remove inhaled particles and pathogens which are trapped in the second layer, the mucus. The hydration of ASL and its height at $\sim 10 \mu \mathrm{m}$ have to be optimal for an efficient mucociliary clearance [39]. The transepithelial movement of $\mathrm{Cl}^{-}, \mathrm{Na}^{+}$and $\mathrm{K}^{+}$are mainly responsible for the transport of water and therefore the hydration of the ASL. As in other epithelia, $\mathrm{Na}^{+}$is transported from the apical surface to the blood via apical membrane ENaC and the basolateral $\mathrm{Na}^{+} / \mathrm{K}^{+}$-ATPase. The recycling of $\mathrm{K}^{+}$through potassium-selective ion channels across the basolateral membrane provides the driving force for $\mathrm{Cl}^{-}$secretion across the apical membrane. $\mathrm{Cl}^{-}$is secreted from the basolateral to the apical side through the $\mathrm{Na}^{+} / \mathrm{K}^{+} / 2 \mathrm{Cl}^{-}$cotransporter and apical $\mathrm{Cl}^{-}$channels such as the cystic fibrosis transmembrane conductance regulator (CFTR) or $\mathrm{Ca}^{2+}$-dependent $\mathrm{Cl}^{-}$channels such as TMEM16A.

The pulmonary epithelium is a target for steroid hormones and their effects on lung function, inflammation or immune responses to allergen exposure have been studied in depth. Estrogen has been shown to modulate the innate immune response in the lung. Cystic fibrosis mice when injected with estrogen and then infected with Pseudomonas aeruginosa, increased the number of white blood cells and PMN (polymorpho nuclear neutrophils) in the whole lung and in the broncho-alveolar lavage. E2 exposure in the lung of CF mice increased the inflammatory infiltrate, mucin and the mRNA levels of Toll Like Receptor 2, InterLeukin (IL)-23 and IL-17A [40]. In the case of allergen exposure in the lung, E2 may have a beneficial effect. Indeed, male mice, nebulised with ovalbumin for 10 days and then challenged with methacholine, developed airway hyperresponsiveness whereas female mice undergoing the same protocol did not show a hyperactive airway [41]. In relation to asthmatic responses it has also been described that E2 could prevent the cholinergic constriction of tracheal rings [42].

In contrast, little is known about the effect of female hormones on airway epithelial ion transport. The few published studies show that estrogen may modulate ion transport in airway epithelial cells and that this can have beneficial or deleterious effects depending on the tissue compartment and on the physiology/pathophysiology state of the airway. For example, it has been described that after an episode of respiratory distress syndrome (RDS), female patients show a much more efficient airway fluid clearance as well as a higher survival rate [43]. It has also been shown that preterm babies have a much lower plasma concentration of estrogen and progesterone and that the infants given estrogen supplement have less severe RDS and improved survival [44]. These studies suggest a role for female hormones in airway fluid clearance and lung development. This conclusion is strengthened by a study in newborn piglets that prenatal estrogen and progesterone deprivation, by the use of specific estrogen and progesterone receptor antagonists, impaired the formation of the alveolar compartments and decreased the amiloride sensitive airway fluid clearance [45].

Thus it would appear that estrogen can affect $\mathrm{Na}^{+}$reabsorption and fluid clearance in the lung. The first study to indicate such a role for E2 came from Sweezey et al. in 1998 showing an increase in ENaC activity and mRNA copies in isolated alveolar type II epithelial cells [46]. A later study by Laube et al. described that a cocktail of estrogen and progesterone increased basal short-circuit current as well as amiloride- and ouabain-sensitive currents in alveolar epithelial cells. This study also showed that these hormones increased the mRNA expression levels of $\alpha$ - and $\beta$-ENaC subunits and the $\mathrm{Na}^{+} / \mathrm{K}^{+}$-ATPase $\beta 1$ subunit [44]. These results further indicate a regulatory role for female sex hormones on $\mathrm{Na}^{+}$ absorption in airway epithelium with a physiological consequence for alveolar airway fluid clearance.

Although estrogen may have beneficial effects on innate immune responses in allergic asthma and on fluid clearance in RDS, 
the influence of gender and female sex hormones on lung function in chronic pulmonary diseases is not straight-forward [47]. In some chronic inflammatory lung diseases such as cystic fibrosis (CF), estrogen is reported to exacerbate lung function - the so-called $\mathrm{CF}$ gender gap. Moreover, it has been described that lung function changes with the menstrual cycle phase in women with CF [48].

The amiloride-insensitive nasal potential difference (NPD) was found to be increased in $\mathrm{CF}$ female patients during the luteal phase (high estrogen + progesterone concentration) of the menstrual cycle when compared to the follicular phase [49], probably due to an altered transepithelial $\mathrm{Na}^{+}$absorption. Other groups have studied the effect of estrogen on $\mathrm{Cl}^{-}$transport in $\mathrm{CF}$ female patients and in $\mathrm{CF}$ bronchial epithelial cell lines. Fanelli et al. showed an increase of $\mathrm{Cl}^{-}$efflux in the CF bronchial epithelial cell line CFBE41oafter $17 \beta$-estradiol treatment. This effect was due to an increase in F508del-CFTR in the apical membrane through the up-regulation of NHERF1 [50]. In 2008, Coakley et al., showed a decrease in UTP induced nasal potential difference variation during high estrogen blood levels in CF and non-CF female patients [51]. From this observation, they studied the effect of estrogen on nucleotidemediated ASL regulation and found that E2 decreased $\mathrm{Ca}^{2+}$ signaling and impaired ASL volume homeostasis through the estrogen receptor ER $\alpha$. A recent study has shown a compromised IL-8 response in inflammation with estrogen treatment in CF bronchial epithelium [52]. Taken together, these studies in bronchial and alveolar epithelia indicate a physiological role for sex-specific actions of estrogen on airway ion transport and fluid clearance in the normal lung and a pathophysiological role in exacerbation of lung function in cystic fibrosis.

\section{Estrogen regulation of ion transport in intestinal epithelium}

The large intestine plays a major role in regulation of wholebody water and salt homeostasis. The distal colon is the main site for water conservation in the body. Every day 1-1.5 l of fluid enters the colon with only $0.1-0.21$ being lost in the feces under normal conditions. This fluid movement is supported by two transport processes: $\mathrm{Na}^{+}$absorption and $\mathrm{Cl}^{-}$secretion. $\mathrm{Na}^{+}$absorption through the $\mathrm{Na}^{+} / \mathrm{H}^{+}$exchanger NHE1 in the small intestine and via $\mathrm{ENaC}$ in the colon permits the absorption of water from the feces under physiological conditions. $\mathrm{ENaC}$ in the intestine is activated by aldosterone or low plasma $\mathrm{Na}^{+}$. This channel constitutes the electrogenic pathway for intestinal $\mathrm{Na}^{+}$absorption regulated by steroid hormones. The colonic epithelium is a major site for neurohumoral regulated $\mathrm{Cl}^{-}$secretion, which serves to ensure the mucosal hydration and the lubrification necessary for the passage of the fecal matter through the colon. $\mathrm{Cl}^{-}$secretion is a complex mechanism involving different ion channels and transporters. $\mathrm{Cl}^{-}$is transported into the cell basolaterally through the $\mathrm{Na}^{+} / \mathrm{K}^{+} /$ $2 \mathrm{Cl}^{-}$co-transporter NKCC1 and is secreted across the apical membrane through the cystic fibrosis transmembrane conductance regulator (CFTR). The electrochemical driving force for $\mathrm{Cl}^{-}$secretion is provided by $\mathrm{K}^{+}$recycling across the basolateral membrane via two types of channels, KCNN4 and KCNQ1 potassium channels. $\mathrm{Cl}^{-}$ secretion may be activated by two different pathways. The cAMP-mediated $\mathrm{Cl}^{-}$secretion is activated by secretagogues that increase intracellular cAMP levels which also activate KCNQ1:KCNE3 channels. The calcium mediated $\mathrm{Cl}^{-}$secretion is activated following a rise in intracellular calcium and a stimulation of calciumdependent apical $\mathrm{Cl}^{-}$channels and basolateral KCNN4 channels [53]. Interestingly, estrogen has been described as a salt retaining steroid hormone, high estrogen states produce an increase in whole body fluid and salt retention. Moreover distal colon has been identified as a target tissue for $17 \beta$-estradiol; indeed colonic crypts express both estrogen receptor isoforms, ER $\alpha$ and ER $\beta$ [54]. Our laboratory first described the inhibitory role of estrogen on epithelial $\mathrm{Cl}^{-}$secretion in the female distal colonic crypts [55]. The anti-secretory response to estrogen in the intestine occurs in a sex specific manner, no effects on secretion were found in male rats, and estradiol inhibited both basal and secretagogue-induced $\mathrm{Cl}^{-}$secretion in female rats. The potency of the E2 anti-secretory response varied with the stage of estrous cycle and was rapid in onset, non-genomic and involved the activation of specific PKC isoforms [56,57]. This study established a physiological role for estrogen as a regulator of $\mathrm{Cl}^{-}$secretion in order to contribute to the E2-induced salt and water retention observed during the high estrogen states [58].

\subsection{Estrogen regulation of KCNQ1:KCNE3 potassium channels}

Studies from our laboratory have determined the molecular mechanisms for E2 inhibition of $\mathrm{Cl}^{-}$secretion via the modulation of KCNQ1:KCNE3 potassium channels in the basolateral membrane [59]. KCNQ1 is a voltage-gated $\mathrm{K}^{+}$channel expressed in a wide range of tissues and can associate with the KCNE family of regulatory subunits, which is made up of five isoform members. The expression of KCNE isoforms is tissue specific. The association between KCNQ1 and a specific KCNE subunit can drastically change the electrophysiological properties of the channel [60]. For example KCNQ1 expressed with KCNE1 produces the delayed rectifier channel expressed in the heart and essential for the cardiac action potential repolarization. In the distal colon, KCNQ1 is expressed with KCNE3 and this association causes KCNQ1 to function as a constitutively activated $\mathrm{K}^{+}$channel. This electrophysiological characteristic fits with the function of KCNQ1 in epithelial cell $\mathrm{K}^{+}$recycling [61]. The molecular mechanisms leading to KCNQ1 inhibition by estrogen involves PKC $\delta$ and PKACI activation, and subsequent KCNE3 phosphorylation and dissociation from KCNQ1 causing a rapid decrease in channel conductance [56]. The sexual dimorphism in the E2 response can be explained, at least in part, by the higher expression of $\mathrm{PKC} \delta$ in female than in the male tissue. Moreover PKC $\delta$ and PKA expression were shown to fluctuate throughout the estrous cycle with a correlation between high levels of protein kinase expression and the potency of the anti-secretory effect of E2 [57]. Thus it appears that KCNE3 plays a critical role in the sex-specific actions of estrogen on epithelial $\mathrm{Cl}^{-}$secretion. In colonocytes KCNE3 increases KCNQ1 channel open probability at the resting membrane potential and KCNE3 is more expressed in male tissue than in female in which expression is also estrous cycle dependent. When plasma E2 levels are high, KCNE3 expression is lower. Importantly, the $\mathrm{E} 2$ effects on $\mathrm{K}^{+}$channel subunit association appears to be specific to KCNQ1:KCNE3 and other channel subunit isoform complexes are unaffected such as KCNE2 or KCNE1 association with KCNQ1. This specificity should confer a tissue-specific effect of estrogen on $\mathrm{K}^{+}$channel activity in the intestine and airway epithelia where KCNQ1:KCNE3 predominates, leaving the heart channel KCNQ1:KCNE1 unaffected. Patch-clamp experiments in $\mathrm{CHO}$ cells have demonstrated the molecular mechanism for E2 inhibition of KCNQ1:KCNE3 channel current via PKC $\delta$ phosphorylation of KCNE3 at the S82 amino acid site [59] with the subsequent uncoupling between KCNE3 and KCNQ1 leading to KCNQ1 inactivation and loss of the electrochemical driving force for $\mathrm{Cl}^{-}$ secretion.

The inhibition of intestinal $\mathrm{Cl}^{-}$secretion in high estrogen states may be a physiological protective response against secretory diarrhea during the estrous cycle. Secretory diarrhea results in excessive loss of body fluids causing life-threatening dehydration and electrolyte imbalance. The main causes of secretory diarrhea in humans are toxins secreted by Vibrio cholerae toxin (CT) and Escherichia coli heat-stable enterotoxin (STa). These toxins stimulate cAMP or cGMP production which leads to a pronounced and 
sustained $\mathrm{Cl}^{-}$secretion. A recent study has shown that $17 \beta$-estradiol rapidly inhibits and even prevents $\mathrm{Cl}^{-}$secretion induced by the bacterial toxins CT and STa in female rat colonic crypts. The E2 inhibition of toxin induced intestinal secretion occurs via sexspecific PKC $\delta$ dependent modulation of KCNQ1:KCNE3 channels to reduce the driving force for $\mathrm{Cl}^{-}$secretion [61].

\subsection{Estrogen regulation of TRPV6 calcium ion channels}

Modulation of intracellular free calcium ion activity is a crucial signal for initiation of many important processes including gene transcription, cell growth and proliferation, neurotransmitter release [62]. Since the whole body $\mathrm{Ca}^{2+}$ homeostasis is dependent on gastrointestinal $\mathrm{Ca}^{2+}$ uptake, it is essential to understand the regulation of intestinal $\mathrm{Ca}^{2+}$ absorption [63]. In rat female colonic crypt, E2 rapidly stimulates a calcium influx through a nongenomic mechanism. It has been shown that this effect was gender-specific and mediated by PKC and PKA dependent signaling pathways [64]. Further studies carried out in another model of colonic epithelium, the T84 cell line, correlated this effect of E2 on $\mathrm{Ca}^{2+}$ influx with the E2 modulation of the endogenous Transient Receptor Potential Vaniloid 6 (TRPV6) channel. TRPV6 is an epithelial $\mathrm{Ca}^{2+}$ channel strongly expressed in colonic epithelium and has been proposed to be the molecular pathway for capacitative calcium entry and to play a significant role in intestinal $\mathrm{Ca}^{2+}$ absorption [65]. Using siRNA directed against TRPV6 it has been demonstrated that TRPV6 is the molecular target for the E2 effect on $\mathrm{Ca}^{2+}$ influx in intestinal epithelium [66]. These studies taken together suggest that estrogen is a major hormonal regulator of intestinal $\mathrm{Ca}^{2+}$ intake as a result of TRPV6 channel modulation.

\section{Conclusions}

Estrogen regulation of the epithelial $\mathrm{Na}^{+}$channel in kidney cortical collecting duct cells can mimic the effects of aldosterone to enhance $\mathrm{Na}^{+}$reabsorption, revealing previously unknown renal responses to estrogen (Fig. 1). In the lung, the combined proabsorptive action of E2 through the activation of ENaC and the anti-secretory response cause a reduction in the volume of airway surface liquid lining the bronchial epithelium. Such ion transport responses to E2 in airway epithelia are female sex-specific and may underlie the CF gender gap where females with cystic fibrosis have exacerbated lung function after puberty and during the midestrous cycle when circulating plasma levels of E2 are highest (Fig. 1). In the intestine, one of E2 main targets is KCNQ1:KCNE3 channel and its inhibition leads to a decrease in $\mathrm{Cl}^{-}$secretion, thus regulating whole body fluid balance (Fig. 1). Extracellular fluid volume expansion is a feature of high estrogen states such as occur in mid-term of the menstrual cycle, use of oral contraceptives and assisted in vitro fertilization. The pro-absorptive, anti-secretory effects of estrogen may underlie this ECF volume expansion. The physiological role of estrogen regulation of ion channels in epithelia of kidney, intestine and lung which regulate whole body fluid and electrolyte balance may be to maintain endometrial expansion necessary for implantation of the blastocyst and to enhance cardiovascular dynamics during pregnancy.

\section{Acknowledgments}

Supported by Grants from the Higher Education Authority PRTLI4 National Biophotonics \& Imaging Platform Ireland and EU Marie-Curie CEMP Cofund grants to B.J.H.

\section{References}

[1] O'Mahony F, Thomas W, Harvey BJ. Novel female sex-dependent actions of oestrogen in the intestine. J Physiol 2009;587:5039-44.

[2] Fourkiotis VG, Hanslik G, Hanusch F, Lepenies J, Quinkler M. Aldosterone and the kidney. Horm Metab Res 2011 [Epub ahead of print].

[3] Arroyo JP, Ronzaud C, Lagnaz D, Staub O, Gamba G. Aldosterone paradox: differential regulation of ion transport in distal nephron. Physiology (Bethesda) 2011;26:115-23.

[4] Briet M, Schiffrin EL. Aldosterone: effects on the kidney and cardiovascular system. Nat Rev Nephrol 2010;6:261-73.

[5] Bugaj V, Pochynyuk O, Stockand JD. Activation of the epithelial Na+ channel in the collecting duct by vasopressin contributes to water reabsorption. Am J Physiol Renal Physiol 2009;297:F1411-8.

[6] Christensen BM, Perrier R, Wang Q, Zuber AM, Maillard M, Mordasini D, et al. Sodium and potassium balance depends on alphaENaC expression in connecting tubule. J Am Soc Nephrol 2010;21:1942-51.

[7] Deng W, Wang DX, Zhang W, Li CY. Regulation of epithelial sodium channel alpha-subunit expression. Chin Med J (Engl) 2011;124:1551-5.

[8] Ergonul Z, Frindt G, Palmer LG. Regulation of maturation and processing of ENaC subunits in the rat kidney. Am J Physiol Renal Physiol 2006;291:F683-93.

[9] Hamm LL, Feng Z, Hering-Smith KS. Regulation of sodium transport by ENaC in the kidney. Curr Opin Nephrol Hypertens 2010;19:98-105.

[10] Lastra G, Dhuper S, Johnson MS, Sowers JR. Salt, aldosterone, and insulin resistance: impact on the cardiovascular system. Nat Rev Cardiol 2010;7:577-84.

[11] Schild L. The epithelial sodium channel and the control of sodium balance. Biochim Biophys Acta 2010;1802:1159-65.

[12] Shibata S, Fujita T. The kidneys and aldosterone/mineralocorticoid receptor system in salt-sensitive hypertension. Curr Hypertens Rep 2011;13:109-15.

[13] Thomas W, Harvey BJ. Mechanisms underlying rapid aldosterone effects in the kidney. Annu Rev Physiol 2011;73:335-57.

[14] Dooley R, Harvey BJ, Thomas W. Non-genomic actions of aldosterone: from receptors and signals to membrane targets. Mol Cell Endocrinol 2012;350(2):223-34.

[15] Harvey BJ, Higgins M. Nongenomic effects of aldosterone on $\mathrm{Ca}^{2+}$ in $\mathrm{M}-1$ cortical collecting duct cells. Kidney Int 2000;57:1395-403.

[16] Thomas W, McEneaney V, Harvey BJ. Aldosterone-induced signalling and cation transport in the distal nephron. Steroids 2008 Oct;73(9-10):979-84.

[17] Harvey BJ, Alzamora R, Stubbs AK, Irnaten M, McEneaney V, Thomas W. Rapid responses to aldosterone in the kidney and colon. J Steroid Biochem Mol Biol. 2008;108(3-5):310-7.

[18] Thomas W, McEneaney V, Harvey BJ. Rapid responses to steroid hormones in the kidney. Nephron Physiol 2007;107(1):p1-9.

[19] Preedy JR, Aitken EH. The effect of estrogen on water and electrolyte metabolism. I. The normal. J Clin Invest 1956;35:423-9.

[20] Dignam WS, Voskian J, Assali NS. Effects of estrogens on renal hemodynamics and excretion of electrolytes in human subjects. J Clin Endocrinol Metab 1956;16:1032-42.

[21] Johnson JA, Davis JO. The effect of estrogens on renal sodium excretion in the dog. Perspect Nephrol Hypertens 1976;5:239-48.

[22] Crocker AD. Variations in mucosal water and sodium transfer associated with the rat oestrous cycle. J Physiol 1971;214:257-64.

[23] Arias-Loza PA, Muehlfelder M, Elmore SA, Maronpot R, Hu K, Blode $\mathrm{H}$, et al. Differential effects of 17beta-estradiol and of synthetic progestins on aldosterone-salt-induced kidney disease. Toxicol Pathol 2009;37:969-82.

[24] Zheng W, Shi M, You SE, Ji H, Roesch DM. Estrogens contribute to a sex difference in plasma potassium concentration: a mechanism for regulation of adrenal angiotensin receptors. Gend Med 2006;3:43-53.

[25] Brunette MG, Leclerc M. Effect of estrogen on calcium and sodium transport by the nephron luminal membranes. J Endocrinol 2001;170:441-50.

[26] Irnaten M, Blanchard-Gutton N, Praetorius J, Harvey BJ. Rapid effects of 17beta-estradiol on TRPV5 epithelial $\mathrm{Ca}^{2+}$ channels in rat renal cells. Steroids 2009;74:642-9.

[27] Hoffmeister MV, Damkier HH, Christensen BM, Olde B, Leeb-Lundberg LM, Fenton RA, et al. 17 beta\}-estradiol induces non-genomic effects in renal intercalated cells through the G-protein coupled estrogen receptor 1 . Am J Physiol Renal Physiol 2011.

[28] Tremblay AM, Dufour CR, Ghahremani $M$, Reudelhuber TL, Giguère V. Physiological genomics identifies estrogen-related receptor alpha as a regulator of renal sodium and potassium homeostasis and the reninangiotensin pathway. Mol Endocrinol 2010;24(1):22-32.

[29] Lee IH, Campbell CR, Cook DI, Dinudom A. Regulation of epithelial $\mathrm{Na}^{+}$ channels by aldosterone: role of Sgk1. Clin Exp Pharmacol Physiol 2008;35:235-41.

[30] Bubien JK. Epithelial $\mathrm{Na}^{+}$channel (ENaC), hormones, and hypertension. J Biol Chem 2010;285:23527-31.

[31] Butterworth MB. Regulation of the epithelial sodium channel (ENaC) by membrane trafficking. Biochim Biophys Acta 2010;1802:1166-77.

[32] Gambling L, Dunford S, Wilson CA, McArdle HJ, Baines DL. Estrogen and progesterone regulate alpha, beta, and gammaENaC subunit mRNA levels in female rat kidney. Kidney Int 2004;65:1774-81. 
[33] Riazi S, Maric C, Ecelbarger CA. 17-beta Estradiol attenuates streptozotocininduced diabetes and regulates the expression of renal sodium transporters. Kidney Int 2006;69:471-80.

[34] Chang CT, Sun CY, Pong CY, Chen YC, Lin GP, Chang TC, et al. Interaction of estrogen and progesterone in the regulation of sodium channels in collecting tubular cells. Chang Gung Med J 2007;30:305-12.

[35] Palmer LG, Frindt G. Aldosterone and potassium secretion by the cortical collecting duct. Kidney Int 2000;57:1324-8.

[36] Wang WH, Giebisch G. Regulation of potassium $(\mathrm{K})$ handling in the renal collecting duct. Pflugers Arch 2009;458:157-68.

[37] Sandhu S, Silbiger SR, Lei J, Neugarten J. Effects of sex hormones on fluid and solute transport in Madin-Darby canine kidney cells. Kidney Int 1997;51:1535-9.

[38] Hoenderop JG, van der Kemp AW, Hartog A, van de Graaf SF, van Os CH, Willems PH, et al. Molecular identification of the apical $\mathrm{Ca}^{2+}$ channel in 1,25dihydroxyvitamin D3-responsive epithelia. J Biol Chem 1999;274:8375-8.

[39] Boucher RC. Molecular insights into the physiology of the 'thin film' of airway surface liquid. J Physiol 1999;516(Pt 3):631-8.

[40] Wang Y, Cela E, Gagnon S, Sweezey NB. Estrogen aggravates inflammation in Pseudomonas aeruginosa pneumonia in cystic fibrosis mice. Respir Res 2010;11:166.

[41] Matsubara S, Swasey CH, Loader JE, Dakhama A, Joetham A, Ohnishi H, et al. Estrogen determines sex differences in airway responsiveness after allergen exposure. Am J Respir Cell Mol Biol 2008;38:501-8.

[42] Dimitropoulou C, White RE, Ownby DR, Catravas JD. Estrogen reduces carbachol-induced constriction of asthmatic airways by stimulating largeconductance voltage and calcium-dependent potassium channels. Am J Respir Cell Mol Biol 2005;32:239-47.

[43] Bastarache JA, Ong T, Matthay MA, Ware LB. Alveolar fluid clearance is faster in women with acute lung injury compared to men. J Crit Care 2011;26:249-56.

[44] Laube M, Kuppers E, Thome UH. Modulation of sodium transport in alveolar epithelial cells by estradiol and progesterone. Pediatr Res 2011;69:200-5.

[45] Trotter A, Ebsen M, Kiossis E, Meggle S, Kueppers E, Beyer C, et al. Prenata estrogen and progesterone deprivation impairs alveolar formation and fluid clearance in newborn piglets. Pediatr Res 2006;60:60-4.

[46] Sweezey N, Tchepichev S, Gagnon S, Fertuck K, O'Brodovich H. Female gender hormones regulate mRNA levels and function of the rat lung epithelial $\mathrm{Na}$ channel. Am J Physiol 1998;274:C379-86.

[47] Tam A, Morrish D, Wadsworth S, Dorscheid D, Man SF, Sin DD. The role of female hormones on lung function in chronic lung diseases. BMC Women Health 2011;11:24.

[48] Johannesson M, Ludviksdottir D, Janson C. Lung function changes in relation to menstrual cycle in females with cystic fibrosis. Respir Med 2000;94:1043-6.

[49] Sweezey NB, Smith D, Corey M, Ellis L, Carpenter S, Tullis DE, et al. Amilorideinsensitive nasal potential difference varies with the menstrual cycle in cystic fibrosis. Pediatr Pulmonol 2007;42:519-24.

[50] Fanelli T, Cardone RA, Favia M, Guerra L, Zaccolo M, Monterisi S, et al. Betaoestradiol rescues DeltaF508CFTR functional expression in human cystic fibrosis airway CFBE41o-cells through the up-regulation of NHERF1. Biol Cell 2008;100:399-412.

[51] Coakley RD, Sun H, Clunes LA, Rasmussen JE, Stackhouse JR, Okada SF, et al. 17beta-Estradiol inhibits $\mathrm{Ca}^{2+}$-dependent homeostasis of airway surface liquid volume in human cystic fibrosis airway epithelia. J Clin Invest 2008;118:4025-35

[52] Chotirmall SH, Greene CM, Oglesby IK, Thomas W, O'Neill SJ, Harvey BJ, McElvaney NG. 17Beta-estradiol inhibits IL-8 in cystic fibrosis by upregulating secretory leucoprotease inhibitor. Am J Respir Crit Care Med 2010;182(1):62-72.

[53] Heitzmann D, Warth R. Physiology and pathophysiology of potassium channels in gastrointestinal epithelia. Physiol Rev 2008;88:1119-82.

[54] Thomas ML, Xu X, Norfleet AM, Watson CS. The presence of functional estrogen receptors in intestinal epithelial cells. Endocrinology 1993; 132:426-30.

[55] Condliffe SB, Doolan CM, Harvey BJ. 17beta-oestradiol acutely regulates Clsecretion in rat distal colonic epithelium. J Physiol 2001;530:47-54.

[56] O'Mahony F, Alzamora R, Betts V, LaPaix F, Carter D, Irnaten M, et al. Female gender-specific inhibition of KCNQ1 channels and chloride secretion by 17beta-estradiol in rat distal colonic crypts. J Biol Chem 2007;282:24563-73.

[57] O'Mahony F, Alzamora R, Chung HL, Thomas W, Harvey BJ. Genomic priming of the antisecretory response to estrogen in rat distal colon throughout the estrous cycle. Mol Endocrinol 2009;23:1885-99.

[58] O'Mahony F, Harvey BJ. Sex and estrous cycle-dependent rapid protein kinase signaling actions of estrogen in distal colonic cells. Steroids 2008;73: 889-94.

[59] Alzamora R, O’Mahony F, Bustos V, Rapetti-Mauss R, Urbach V, Cid LP, et al. Sexual dimorphism and oestrogen regulation of KCNE3 expression modulates the functional properties of KCNQ1 K channels. J Physiol 2011;589: 5091-107.

[60] Jespersen T, Grunnet M, Olesen SP. The KCNQ1 potassium channel: from gene to physiological function. Physiology (Bethesda) 2005;20:408-16.

[61] Alzamora R, O’Mahony F, Harvey BJ. Estrogen inhibits chloride secretion caused by cholera and Escherichia coli enterotoxins in female rat distal colon. Steroids 2011;76:867-76.

[62] Berridge MJ, Lipp P, Bootman MD. The versatility and universality of calcium signalling. Nat Rev Mol Cell Biol 2000;1:11-21.

[63] Hurwitz S. Homeostatic control of plasma calcium concentration. Crit Rev Biochem Mol Biol 1996;31:41-100.

[64] Doolan CM, Condliffe SB, Harvey BJ. Rapid non-genomic activation of cytosolic cyclic AMP-dependent protein kinase activity and $[\mathrm{Ca}(2+)](\mathrm{i})$ by 17 betaoestradiol in female rat distal colon. Br J Pharmacol 2000;129:1375-86.

[65] Peng JB, Brown EM, Hediger MA. Epithelial $\mathrm{Ca}^{2+}$ entry channels: transcellular $\mathrm{Ca}^{2+}$ transport and beyond. J Physiol 2003;551:729-40.

[66] Irnaten M, Blanchard-Gutton N, Harvey BJ. Rapid effects of 17beta-estradiol on epithelial TRPV6 $\mathrm{Ca}^{2+}$ channel in human T84 colonic cells. Cell Calcium 2008;44:441-52. 